\title{
The LUCID study: living with ulcerative colitis; identifying the socioeconomic burden in Europe
}

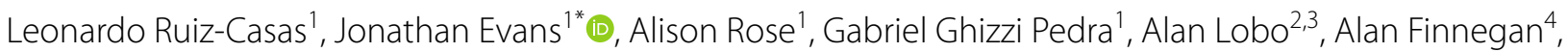
Bu Hayee ${ }^{5}$, Laurent Peyrin-Biroulet ${ }^{6}$, Andreas Sturm $^{7}$, Johan Burisch ${ }^{8}$, Helen Terry ${ }^{9}$, Luisa Avedano ${ }^{10}$, Seb Tucknott ${ }^{11}$, Gionata Fiorino ${ }^{12}$ and Jimmy Limdi ${ }^{13}$

\begin{abstract}
Background: Ulcerative colitis (UC) is an inflammatory bowel disease with increasing prevalence worldwide. Current treatment strategies place considerable economic and humanistic burdens on patients. The aim of this study was to determine the socioeconomic burden of UC in adult patients in European countries in a real-world setting.

Methods: In this retrospective, cross-sectional and observational pan-European study, patients with moderate or severe UC were assigned to ARM 1 and patients who had moderate or severe UC but achieved mild or remission status 12 months before index date (or clinical consultation date), were assigned to ARM 2. Clinical and medical resource use data were collected via electronic case report forms, and data on non-medical and indirect costs, and healthrelated quality of life (HRQoL) were collected via patient and public involvement and engagement (PPIE) questionnaires. Per-patient annual total costs per ARM and per country were calculated using the collated resource use in the last 12 months (between the start of the documentation period and patient consultation or index date) and country specific unit costs. Quality of life was described by arm and by country.
\end{abstract}

Results: In the physician-reported eCRF population $(n=2966)$, the mean annual direct medical cost was $€ 4065$ in ARM $1(n=1835)$ and $€ 2935$ in ARM 2 ( $n=1131)$. In the PPIE population (ARM 1, $n=1001$; ARM 2, $n=647)$, mean annual direct cost was $€ 4526$ in ARM 1 and $€ 3057$ in ARM 2, mean annual direct non-medical cost was $€ 1162$ in ARM 1 and $€ 1002$ in ARM 2, mean annual indirect cost was $€ 3098$ in ARM 1 and $€ 2309$ ARM 2, and mean annual total cost was in $€ 8787$ in ARM 1 and $€ 6368$ in ARM 2. HRQoL scores showed moderate to high burden of UC in both groups.

Conclusions: The cost and HRQOL burden were high in patients in both ARM 1 and ARM 2 indicating unmet needs in the UC active population.

Keywords: Ulcerative colitis, Health-related quality of life, Socioeconomic burden

*Correspondence: jonathan.evans@hcdeconomics.com

${ }^{1}$ HCD Economics, The Innovation Centre, Keckwick Lane, Daresbury, Warrington, England, UK

Full list of author information is available at the end of the article

\section{Background}

Ulcerative colitis (UC) is a chronic, relapsing and remitting and potentially progressive form of inflammatory bowel disease (IBD) of uncertain aetiology, characterised by inflammation localised in the mucosa of the rectum and colon [1-3]. UC can lead to disease complications (strictures, bowel perforations and toxic megacolon, among others) and extraintestinal manifestations 
(EIM) in other tissues and organs, including the skin, joints, eyes, mouth, liver and lungs $[4,5]$. It has an estimated incidence of $1.2-20.3$ per 100,000 and a prevalence of 7.6-245 per 100,000 [6-10].

Current UC treatment strategies include medications that aim to induce and maintain clinical remission, prevent complications (such as hospitalisation, surgery, colorectal cancer and EIM) and improve health-related quality of life (HRQoL) [4, 11]. Treatment options are usually dictated by severity of disease and patient preference. In most cases, a step-up medication strategy is followed; patients with mild to moderate UC symptoms are usually treated with 5-aminosalicylates and corticosteroids, whereas those with moderate to severe symptoms are treated with corticosteroids, immunosuppressants (such as thiopurines) and more advanced targeted therapies such as monoclonal antibodies and more recently an orally administered JAK inhibitor [2-4]. Despite an expanding armamentarium of therapeutic options, the fluctuating course of UC and often unpredictable response to treatment implies that patients often experience disease "flares" requiring urgent out-patient consultations, hospitalisation and surgery for symptoms driven by refractory inflammation, complications of disease and hitherto under-recognised morbidity from chronic pain and psychosomatic issues [12-18].

Exacerbation of UC symptoms has a significant impact on health-care utilisation with annual costs of UC care reported to be as high as USD 8.1-14.9 billion in the USA and Euros 12.5-29.1 billion in Europe. In 2006, the mean annual expenditure on healthcare for UC across several European countries was estimated to be $€ 1524$ per patient, and the most expensive costs were medical and surgical hospitalisations accounting for $45 \%$ of the total expenditure [19]. Frequent health care utilisation and active UC (periods of high intensity of symptoms) contributes to work absenteeism and disability, with a significant negative impact on HRQoL [19, 20]. Furthermore, fatigue, feeling of isolation and loss of control may also negatively impact of quality of life and psychosocial well-being of patients and indeed health-care utilisation through direct and indirect costs of care $[12-15,17,18$, $21,22]$.

Despite increasing awareness of economic and humanistic burdens of UC, there is a lack of extensive, up-todate and real-world information on the socioeconomic burden of active UC.

The overall aim of this study was to provide robust evidence for the identification of the overall socioeconomic burden of UC in the EU5 (France, Germany, Italy, Spain, United Kingdom [UK]), Denmark, Norway, Poland, Romania and Turkey in a real-world setting.
The primary objective of this study was to explore and quantify the annual costs of living with active UC from a societal perspective (including direct medical, non-medical and indirect costs), and the secondary objective was to explore the effect of UC on the HRQoL and productivity using patient-reported outcomes measurements (PROMs) and work-related activity. Patient stratification by country and by disease severity added granularity to the analyses.

\section{Methods \\ Study design}

This was a non-interventional, descriptive, retrospective, cross-sectional, pan-European (EU5, Denmark, Norway, Poland, Romania, and Turkey) multi-site study. Gastroenterologists were recruited over the study period between August 2018-February 2019. Each gastroenterologist provided data from the medical records of their patients using standardised questionnaires called electronic Case Report Forms (eCRFs) for up to 10 eligible patients with UC per ARM (20 in total).

\section{Participants}

The primary and secondary objectives were analysed by disease severity (two ARMs of the study) and country. The index date was defined as the date of clinical consultation between the patient and the participating physician. ARM 1 included patients with moderate or severe $\mathrm{UC}$ at initiation of the documentation period (12 months prior to the index date) as indicated by the Mayo score, simple clinical colitis activity index (SCCAI) scores, or physician global assessment for UC. ARM 2 included patients with moderate or severe UC 24 months prior to the index date that achieved mild UC or remission at initiation of documentation period (12 months prior to the index date) as indicated by Mayo score or SCCAI scores for UC, or physician global assessment (Fig. 1). Clinical remission was defined as a Mayo score of $0-2$, PGA of 0 or SCCAI $<2$. Mild UC was defined as a Mayo score of 3-5, PGA of 1 or SCCAI 2-4. Moderate-severe disease was defined by as a Mayo score of $6-10$ (moderate) and 11-12-9 (severe), PGA of 2(moderate), PGA 3(severe) or SCCAI $>5$. ARM 1 and ARM2 definitions were independent of the fact that patient's severity status could fluctuate within the documentation period (as this was the case in both arms, due to the fluctuant nature of the disease).

\section{Patient inclusion criteria}

Patients were included in the study if they were 18 years or older at the index date, with UC diagnosis confirmed by endoscopy and histology at least 24 months before the index date. Patients in ARM 1 had moderate or severe 


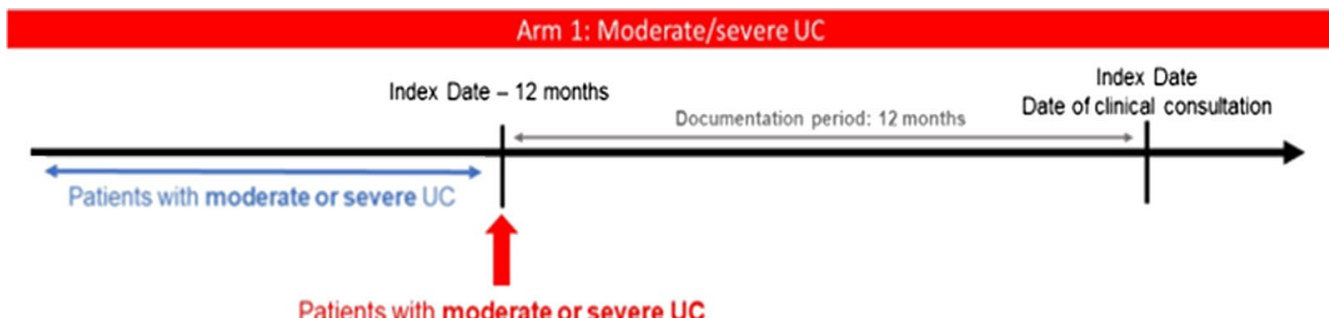

Patients with moderate or severe UC

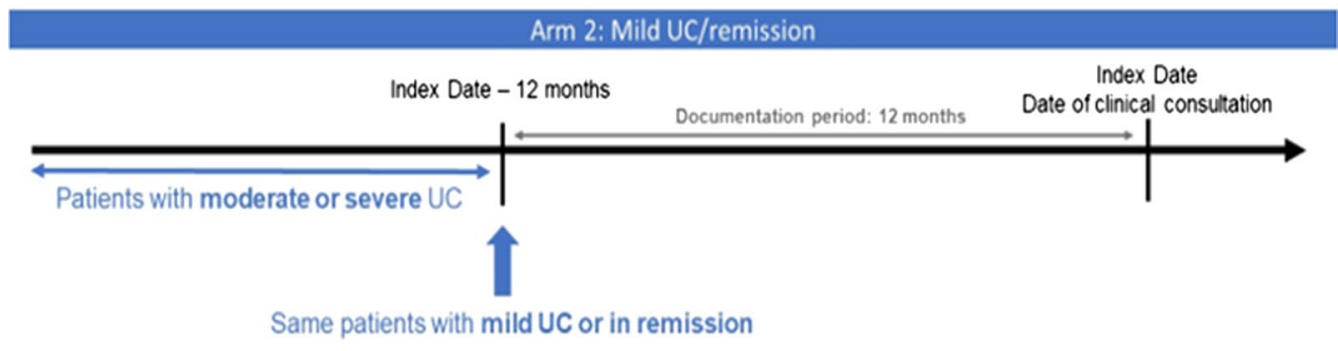

Fig. 1 A representation of the study design, indicating the index date, documentation period and ARMs of study. UC Ulcerative colitis

UC at initiation of documentation period (12 months prior the index date) as indicated by Mayo or Simple Clinical Colitis Activity Index (SCCAI) scores (between 6 and 10 for moderate patients, and score between 11 and 12 for severe patients), or by physician global assessment. Patients in ARM 2 had moderate or severe UC that achieved mild UC or remission at initiation of documentation period (12 months prior the index date), where mild UC was indicated by Mayo or simple clinical colitis activity index (SCCAI) scores (3-5), or by physician global assessment and clinical or endoscopic remission was indicated by Mayo or SCCAI scores (less than 2) or by physician global assessment. Furthermore, patients were required to be able to read, understand and sign the informed consent form in their local language.

\section{Patient exclusion criteria}

Patients were excluded from the study if they were diagnosed with Crohn's Disease and/or IBD unclassified, initiated clinical trials/non-interventional study for IBD and/or UC treatment 12 months prior the index date, could not understand the PPIE questionnaire for issues such as language barriers or suffered from a physical or mental condition that prevented them from providing informed consent.

\section{Variables}

Gastroenterologists provided data on each patient, that included demographic, clinical (disease history, diagnosis, symptoms, complications, etc.) and economic information (direct medical resource utilisation: medications, consultations, hospitalisations and surgical interventions, tests and procedures used for diagnosis and follow-up of disease), via the electronic case report form.

To capture data on HRQoL and other UC-related costs, gastroenterologists invited patients to provide information via patient and public involvement and engagement (PPIE) questionnaires. Data on HRQoL were captured via validated tools such as EuroQol-5D-5L (EQ-5D) [23, 24], the inflammatory bowel disease disability index (IBD-DI) [25] and the IBD control questionnaire (IBD Control Q; UK only) [26]. The work productivity and activity impairment (WPAI) [27] questionnaire were used to capture productivity losses and impairment in daily life activities due to their UC condition.

Data on UC-related costs included direct non-medical costs (professional caregiving, alternative therapies, aids and home equipment/adaptations, transportation and transfer payments-including state benefits or disability allowances) and indirect costs (loss of wages and productivity for patients and their carers due to absenteeism or impairment while at work, including early retirement or long-term sick leaves due to UC).

\section{Data sources}

Clinical health resource use data for each patient was captured in the eCRF while direct non-medical and indirect resource use as well $\mathrm{HRQ}$ oL was captured in the PPIE. National unit costs for each resource item were sourced from country-specific sources, governmental 
documents and national drug pricing databases. A list of used sources for each country is available in Additional file 1: Table 1.

\section{Statistical analysis}

To calculate the cost per ARM, the resource use (RU) and unit cost data were collated using homogeneous collection methods (both CRF and PPIE questionnaires were equal across countries, with some country specific differences to account for differences in health care systems) to ensure international comparability, followed by applying unit costs to RU data for each country.

Per-patient costs for the 12 months between the start of the documentation period and patient consultation or index date were calculated by multiplying the quantities of the resource used with the national unit price of each resource (updated to 2019 prices using inflation indicators via http://ec.europa.eu/eurostat/web/hicp/data/ database). Applying the unit costs was performed via a transparent model design using simple formulae: Price $_{i}$ $\times$ Quantity $_{\mathrm{i}}=$ Cost $_{\mathrm{i}} ; \mathrm{i}=1-\mathrm{n}$ ( $\mathrm{n}=$ number of cost items). Country-specific unit costs were multiplied with the resource use quantity to calculate the mean per-patient UC-related cost for the 12 months prior to index date. All local currency total costs were converted to Euros using the official conversion rates as of $30^{\text {th }}$ of august 2019 (https://www.oanda.com/currency/converter/).

Annual Indirect costs were computed by assigning an opportunity cost (average salaries of the different countries were considered) to the disease-related productivity losses of patients and informal carers. All descriptive analyses were performed using Stata 16.

\section{Ethics}

The study was approved by the Research Ethics Sub Committee of the Faculty of Health and Social care within the University of Chester (UoC). This study complies with UK national requirements and followed the Guidelines for Good Pharmacoepidemiology Practices (GPP) [28]. An Expert Review Group (ERG) was established to ensure the maintenance of quality standards and provide overall study guidance on behalf of HCD Economics, UoC, charity partner Crohn's and Colitis UK (CCUK) and funding sponsors.

\section{Results}

\section{Study population}

The 379 recruited gastroenterologists, primary care and internal medicine practitioners completed electronic CRFs for 2979 patients. Amongst these, 1657 (55\%) patients completed the PPIE which was matched to the corresponding CRF. Patient response rates for the completion of PPIEs questionnaires ranged from $16 \%$ in the
United Kingdom to 95\% in Romania (see Additional file 1: Table 2 for CRF and PPIE response by country), which was a reflection of the voluntary nature of the PPIE completion and patient willingness to contribute (no incentives were given to patients for the completion).

Out of the 2979 CRFs, 1835 were assigned to ARM 1, 1131 were assigned to ARM 2, and 13 could not be placed into an ARM due to lack of disease severity data. Disease severity data reflected the fluctuant nature of UC activity, with $39 \%$ of patients in ARM 1 improving to remission or mild status, and $23 \%$ of patients in ARM 2 worsening to moderate or severe status. Gender, age and body mass index (BMI) were largely similar across the two arms (Table 1).

Of the 1657 (55\%) patients who completed the PPIE questionnaire, 1001 were assigned to ARM 1, 647 were assigned to ARM 2 and 9 could not be placed into an ARM due to lack of severity data.

Table 1 Study population demographics

\begin{tabular}{|c|c|c|c|}
\hline & ARM 1 & ARM 2 & Overall \\
\hline Number of patients (\%) & $1835(62)$ & $1131(38)$ & $2966(100)$ \\
\hline Male (\%) & $1023(56)$ & $615(53)$ & $1638(55)$ \\
\hline Female (\%) & $812(44)$ & $516(47)$ & $1328(45)$ \\
\hline $\begin{array}{l}\text { Number of severities (12 months } \\
\text { prior index date) }\end{array}$ & 1835 & 1131 & 2966 \\
\hline Remission (\%) & - & $520(46)$ & $520(17)$ \\
\hline Mild (\%) & - & $611(54)$ & $611(21)$ \\
\hline Moderate (\%) & $1457(79)$ & - & $1457(49)$ \\
\hline Severe (\%) & $378(21)$ & - & $378(13)$ \\
\hline $\begin{array}{l}\text { Number of severities (last } \\
\text { recorded) }\end{array}$ & 1758 & 1104 & 2862 \\
\hline Remission (\%) & $134(8)$ & $300(27)$ & $434(15)$ \\
\hline Mild (\%) & $545(31)$ & $547(50)$ & $1092(38)$ \\
\hline Moderate (\%) & $885(50)$ & $209(19)$ & $1094(38)$ \\
\hline Severe (\%) & $194(11)$ & $48(4)$ & $242(8)$ \\
\hline Age (n) & 1835 & 1131 & 2966 \\
\hline Mean (SD) & $46(15)$ & $48(15)$ & $47(15)$ \\
\hline BMI (n) & 1835 & 1,131 & 2966 \\
\hline Mean (SD) & $24.06(4.2)$ & $24.38(3.8)$ & $24.18(4.1)$ \\
\hline Country (n) & 1835 & 1131 & 2966 \\
\hline Denmark (\%) & $9(36)$ & $16(64)$ & $25(100)$ \\
\hline France (\%) & $336(67)$ & $163(33)$ & $499(100)$ \\
\hline Germany (\%) & $256(76)$ & 79 (24) & $335(100)$ \\
\hline Italy (\%) & $348(62)$ & $217(38)$ & $565(100)$ \\
\hline Norway (\%) & $12(57)$ & $9(43)$ & $21(100)$ \\
\hline Poland (\%) & $132(62)$ & $82(38)$ & $214(100)$ \\
\hline Spain (\%) & $344(58)$ & $250(42)$ & $594(100)$ \\
\hline Turkey (\%) & $42(35)$ & $78(65)$ & $120(100)$ \\
\hline UK (\%) & $256(54)$ & $219(46)$ & $475(100)$ \\
\hline Romania (\%) & $100(85)$ & $18(15)$ & $118(100)$ \\
\hline
\end{tabular}

$B M I$ body mass index, $n$ number, $S D$ standard deviation, UK United Kingdom 


\section{Diagnosis and monitoring}

Most patients in ARM 1 and ARM 2 of the eCRF population had left-sided colitis ( $40 \%$ and $43 \%$, respectively), followed by extensive colitis ( $26 \%$ and $21 \%$, respectively). The mean age of diagnosis was 40.5 years across both ARMs. Across countries, the mean age at diagnosis varied from 35.8 years in Poland to 45.3 years in Italy.

\section{Comorbidities}

In both arms of the eCRF population, $71 \%$ of patients experienced at least one comorbidity; anaemia was the most commonly reported in 34\% of patients (with $38 \%$ and 27\% in ARMS 1 and 2 respectively), followed by anxiety and depression in $31 \%$ and $16 \%$ of patients.

\section{Disease activity}

Patients experienced various symptoms at index date and 12 months prior, where the main five symptoms were diarrhoea $(62 \%$ and $55 \%$ at 12 months prior index date, and $43 \%$ and $30 \%$ at index date in ARM 1 and ARM 2 respectively), rectal bleeding (55\% and $44 \%$ at 12 months prior index date, and $28 \%$ and $14 \%$ at index date in ARM 1 and ARM 2 respectively), anaemia (54\% and $41 \%$ at 12 months prior index date, and $31 \%$ and $19 \%$ at index date in ARM 1 and ARM 2 respectively), cramping pain (47\% and $37 \%$ at 12 months prior index date, and $32 \%$ and 20\% at index date in ARM 1 and ARM 2 respectively) and tiredness/fatigue (38\% and $42 \%$ at 12 months prior index date, and $34 \%$ and $36 \%$ at index date in ARM 1 and ARM 2 respectively).

UC-related complications in patients from ARM 1 and ARM 2 were reported throughout their life, with strictures being the most frequently reported complications (12\% and $9 \%$ respectively), followed by fistulas (10\% and $7 \%$ respectively) and perforations (4\% and 3\% respectively).

Despite patients in ARM 2 achieving mild or remission status at the initiation of the documentation period, the severity of symptoms and complications remained relatively high both at that timepoint but also at index date.

Patients in ARM 1 and ARM 2 experienced anaemia (69\% and 63\%, respectively) and EIMs such as joint inflammation (20\% in both ARMs) and mouth ulcers (13\% and $19 \%$, respectively).

\section{Treatment history}

To relieve the symptoms of UC, conventional non-biologic and biologic therapies were typically prescribed. Non-biologic therapies included mesalazine $(62 \%$ in ARM 1 and 68\% in ARM 2), azathioprine (18\% in ARM 1 and $12 \%$ in ARM 2) and prednisone (15\% in ARM 1 and $8 \%$ in ARM 2), but also less commonly prescribed therapies such as sulfasalazine ( $9 \%$ of all patients), budesonide
(8\%), methotrexate $(4 \%)$ or tacrolimous (1\%). Biologic treatments were prescribed to $22 \%(n=652)$ of the study population, with infliximab (49\% in ARM 1 and 54\% in ARM 2 respectively) and adalimumab (38\% and 35\%) being the most common, and vedolizumab (10\% and $8 \%$ ), golimumab (9\% and 6\%) and others (not specified, $2 \%$ and $1 \%$ ) less commonly prescribed.

Five percent $(n=153)$ of all the patients had undergone at least one surgery for their UC (with 5\% and 6\% of patients of ARM1 and 2 respectively) being colectomy with ileostomy the most frequent procedure $(29 \%$ of these patients) followed by colectomy with ileorectal anastomosis (21\%), ileal pouch-anal anastomosis (15\%), proctocolectomy with permanent ileostomy (12\%), with an additional $25 \%$ of patients that received "other" procedures. An additional $6 \%(n=168)$ of the patients in the LUCID study sample were considered "candidates for surgery", with $6 \%$ and $4 \%$ of patients in ARM 1 and 2 respectively.

\section{Costs}

Table 2 summarises total direct, direct non-medical and medical costs in ARMs 1 and 2.

\section{Direct medical costs (via eCRF)}

Overall mean direct medical costs were $€ 3949$ in the PPIE population $(n=1648)$ and $€ 3634$ in the CRF population $(\mathrm{n}=2966)$ (Table 2).

In the eCRF population, the mean direct medical cost was $€ 4065$ in ARM $1(n=1835)$ and $€ 2935$ in ARM $2(\mathrm{n}=1132)$. The mean cost was highest in Norway (€5373), Germany (€5320), Denmark (€4851) and Italy $(€ 4307)$, and lowest in Turkey (€1299) (Table 3). Biologic treatments incurred the highest mean costs across ARMS 1 and 2 and in every country, except for Turkey, where costs for consultations were higher than biologic treatments.

\section{Direct non-medical (via PPIE)}

Mean annual direct non-medical cost was $€ 1162$ in ARM 1 and $€ 1002$ in ARM 2 (Table 2). The highest overall direct non-medical costs across all countries were observed in the EU5 countries and Poland; the largest was reported in patients from Italy $(€ 1787)$ (Table 3$)$. Professional caregiver costs were the most expensive items across both ARMS and most countries, followed by support services (e.g., nutritionists and physiotherapists) and transfer payments from the government.

\section{Indirect costs (via PPIE)}

Mean annual indirect cost was $€ 3098$ in ARM 1 and $€ 2309$ ARM 2 (Table 2). Most indirect costs were attributed to long term sick leaves and early retirements from 
Table 2 Total direct medical, direct non-medical and indirect costs by ARM

\begin{tabular}{|c|c|c|c|}
\hline & ARM 1 & ARM 2 & Overall \\
\hline CRF population, direct medical cost ( $n$ ) & 1835 & 1131 & 2966 \\
\hline Mean (SD) & $€ 4065(10,182)$ & $€ 2935$ (7327) & $€ 3634$ (9214) \\
\hline Biologic Tx & $€ 2646$ (9285) & $€ 1829(6979)$ & $€ 2334$ (8488) \\
\hline Procedure/Test & $€ 174(215)$ & $€ 174(204)$ & $€ 174(211)$ \\
\hline Non-Biologic Tx & $€ 376$ (1692) & $€ 358(1437)$ & $€ 369$ (1599) \\
\hline Surgery & $€ 87$ (638) & $€ 96(615)$ & $€ 90$ (629) \\
\hline Consultation & $€ 492$ (859) & $€ 402(535)$ & $€ 458(753)$ \\
\hline Hospitalisation & $€ 289$ (1885) & $€ 76(571)$ & $€ 208(1527)$ \\
\hline PPIE population, (n) & 1001 & 647 & 1648 \\
\hline Direct medical cost, mean (SD) & $€ 426(10,849)$ & $€ 3057(7790)$ & $€ 3949$ (9787) \\
\hline Biologic Tx & $€ 3007$ (9718) & $€ 1964$ (7468) & $€ 2,597(8915)$ \\
\hline Procedure/Test & $€ 171(193)$ & $€ 181(177)$ & $€ 175(187)$ \\
\hline Non-Biologic Tx & $€ 396(1780)$ & $€ 394$ (1426) & $€ 395(1650)$ \\
\hline Surgery & $€ 74(471)$ & $€ 63$ (403) & $€ 70(445)$ \\
\hline Consultation & $€ 527(1064)$ & $€ 387(535)$ & $€ 472(897)$ \\
\hline Hospitalisation & $€ 352$ (2238) & $€ 67$ (649) & $€ 240$ (1796) \\
\hline Direct non-medical cost, mean (SD) & $€ 1162(3761)$ & $€ 1002(3276)$ & $€ 1099$ (3578) \\
\hline Professional caregiver & $€ 493$ (3326) & $€ 437(2581)$ & $€ 471(3054)$ \\
\hline Home alteration & $€ 48(187)$ & $€ 41$ (194) & $€ 45$ (190) \\
\hline OTC medication & $€ 80(153)$ & $€ 64$ (124) & $€ 74(142)$ \\
\hline Transport & $€ 96(196)$ & $€ 116(584)$ & $€ 104$ (397) \\
\hline Transfer payments & $€ 218$ (1134) & $€ 129(890)$ & $€ 183(1045)$ \\
\hline Alternative therapy & $€ 227(737)$ & $€ 216(866)$ & $€ 222(790)$ \\
\hline Indirect cost, mean (SD) & $€ 3098$ (9091) & $€ 2309$ (7379) & $€ 2789$ (8467) \\
\hline Non-professional caregiver & $€ 767$ (3689) & $€ 642(2791)$ & $€ 718$ (3365) \\
\hline Retire/stop working & $€ 1456(6724)$ & $€ 1419(6330)$ & $€ 1441(6570)$ \\
\hline Time off work in the last 12 months & $€ 875$ (3311) & $€ 249(1112)$ & $€ 630$ (2689) \\
\hline Total cost PPIE Pop only, mean (SD) & $€ 8787(15,793)$ & $€ 6368(12,149)$ & $€ 7837(14,517)$ \\
\hline
\end{tabular}

CRFs case record forms, $n$ number PPIEs patient public involvement engagement, SD standard deviation, Pop population

patients, with close to $50 \%$ of total indirect costs, whereas time from informal caregivers and time off work in the last 12 months had similar proportions. At the country level, France had the highest recorded mean indirect cost $(€ 4,334)$ followed by Spain $(€ 3061)$, the UK (€3045) and Italy (€2876) (Table 3).

\section{Calculating HRQoL via validated PROMs}

Tables 4, 5 and 6 summarise PPIE population patient responses to the EQ-5D-5L, IBD-DI and WPAI questionnaires.

\section{EQ-5D-5L, IBD-DI and WPAI}

The EQ5D-5L questionnaire was completed by 994 in ARM 1 and 637 patients in ARM 2. The overall mean total EQ-5D index score was 0.83 , with 0.81 and 0.86 in the ARMs 1 and 2, respectively. The EQ-5D scores varied between the countries included in this study. In ARM 1 , the highest EQ-5D score was observed in Norway
(0.91) and the lowest in France (0.8). In ARM 2, the highest EQ-5D score was observed in Denmark (0.95) and the lowest in Romania (0.8) (Table 5). EQ-5D review of dimensions revealed a greater impact in the pain/discomfort and anxiety depression domains across both arms, whereas it showed a limited impact on mobility, self-care and usual activities.

The IBD-DI questionnaire was completed by 1000 patients in ARM 1 and 647 patients in ARM 2. The overall mean total IBD-DI score was 27.3, with 30.6 and 22.3 in ARMs 1 and 2, respectively (Table 4). The highest IBD-DI scores in ARM 1 and ARM 2 were in Italy (35.6) and Romania (30.6) respectively, whereas the lowest scores were in Denmark (19 and 9.6, respectively; Table 5).

In the PPIE population, 1001 patients ARM 1 and 647 patients in ARM 2, completed the work productivity and activity impairment (WPAI) questionnaire. Work productivity loss was the most affected dimension in both 


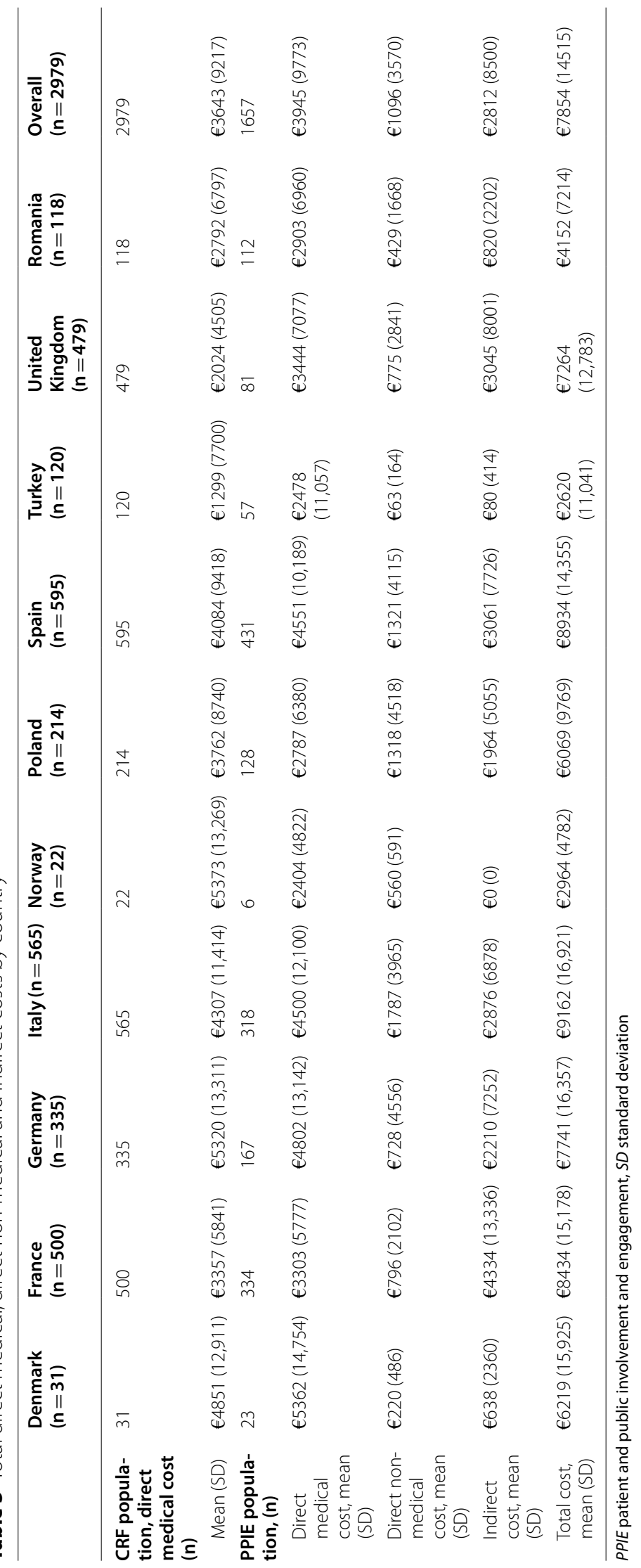


Table 4 Patient-reported IBD-DI, EQ-5D and WPAI scores in the PPIE population by ARM

\begin{tabular}{llll}
\hline & ARM 1 & ARM 2 & Overall \\
\hline EQ-5D total score (n) & 994 & 637 & 1631 \\
$\quad$ Mean (SD) & $0.81(0.17)$ & $0.86(0.16)$ & $0.83(0.17)$ \\
$\quad$ Median (IQR) & $0.84(0.21)$ & $0.90(0.19)$ & $0.86(0.18)$ \\
EQ-5D VAS score (n) & 1001 & 647 & 1648 \\
$\quad$ Mean (SD) & $71.2(18.3)$ & $76.6(16.2)$ & $73.3(17.7)$ \\
$\quad$ Median (IQR) & $75(25)$ & $80(20)$ & $75(25.5)$ \\
IBD-DI score (n) & 1000 & 647 & 1647 \\
$\quad$ Mean (SD) & $30.6(18.9)$ & $22.3(16.6)$ & $27.3(18.5)$ \\
IBD control score, UK only (n) & 29 & 42 & 71 \\
$\quad$ Mean (SD) & $7.1(3.7)$ & $7.3(2.1)$ & $7.2(2.9)$ \\
WPAI Scores in Total PPIE popula- & 1001 & 647 & 1648 \\
tion & & & \\
Work time missed (absenteeism; & $517(52)$ & $324(50)$ & $841(51)$ \\
\%) & & & \\
$\quad$ Mean (SD) & $0.11(0.25)$ & $0.06(0.19)$ & $0.09(0.23)$ \\
Impairment (presenteeism; $\mathbf{n )}$ & $484(48)$ & $315(49)$ & $799(48)$ \\
$\quad$ Mean (SD) & $0.24(0.21)$ & $0.18(0.19)$ & $0.22(0.20)$ \\
Work productivity loss (n) & $484(48)$ & $315(49)$ & $799(48)$ \\
$\quad$ Mean (SD) & $0.28(0.24)$ & $0.20(0.21)$ & $0.25(0.23)$ \\
Activity Impairment (n) & $602(60)$ & $368(57)$ & $970(59)$ \\
$\quad$ Mean (SD) & $0.27(0.24)$ & $0.18(0.20)$ & $0.24(0.23)$ \\
\hline
\end{tabular}

EQ-5D EuroQol-5 dimension, IBD-DI inflammatory bowel disease disability index, $I Q R$ interquartile range, $n$ number, PPIE patient and public involvement and engagement, SD standard deviation, UK United Kingdom, VAS visual analogue scale, WPAI work productivity and activity impairment

arms, with mean scores of 0.28 and 0.20 , respectively (Table 4).

\section{Discussion}

Despite the growing number of cost-effectiveness studies of new pharmacological interventions (biologics), no previous studies have focused on the overall burden of UC, including costs beyond medical management. To our knowledge, this is the first study to adopt a societal perspective at the pan-European level. Compared with indirect costs, the direct medical cost was higher across both arms of the study. Indirect costs, however, were substantial, highlighting the need for a holistic perspective to have a better appreciation on the true cost of care for patients with UC.

Over the years, biologic treatment is the main driver for direct medical costs $[15,17,18,21,22]$. It is likely that their proportion in total costs is smaller than what is stated in this study due to the practical difficulties with capturing real transaction prices and also because this study did not capture the proportion of biosimilar use vs cost of original biologic. Accounting for competitive processes such as regional or hospital tenders, non-transparent price discounts etc. poses real practical challenges and whilst desirable, remain unrealistic and must be acknowledged as a possible limitation of our work.

Patients in ARM 1 reported a higher impairment in both HRQoL and work productivity and activity than patients in ARM 2, suggesting a direct relationship between UC activity and morbidity from disease, however a formal statistical comparison was not the objective of this exploratory study. Patients with active UC have been reported to have higher health care related costs from the direct cost of diagnostic tests, medication, hospitalisation and surgery but also from indirect costs such as reduced employment, effect on work-productivity and opportunities for unpaid activities [29-31]. The EQ-5D-5L show a relatively small impact of the disease in patients, with high scores per ARM, which might be explained by low sensitivity of the measuring instrument, the fluctuating nature of the disease (many patients changed to different severity status in the 12 months documentation period, resulting in mixed results) and recall period of 1 day "your health today". Also, the realistic possibility of corticosteroid therapy in these patients in controlling symptoms but not necessarily achieving meaningful remission may mask true disease activity.

The relatively small differences observed in total costs results in both arms suggest that there are significant unmet needs and associated costs in patients even when they achieve mild and remission status (definition of ARM 2 in this study). Again, the fluctuant nature of disease severity (39\% of patients in ARM 1 improving to mild or remission and $23 \%$ of those in ARM 2 worsening to moderate or severe) may partly explain these results. The ARM- and country-specific IBD-DI scores imply an impact on Quality of Life, but also suggest that the EQ-5D might not be a sensitive enough tool in a disease with a fluctuating nature such as UC. The mean IBD control score, which was only captured in UK patients, was 7.3 in ARM 2 and 7.1 in ARM 1. Therefore, it is recommended to carry out further detailed analysis of the data, focusing on the relationship between changing severity and clinical and economic outcomes.

The proportion of patients with strictures as a complication of their UC was higher than expected at $12 \%$ and 9\% for ARM 1 and ARM 2 respectively. Previous studies have reported a prevalence of $1.5 \%, 3.2 \%$ and $6.5 \%$ respectively [32-34]. It is possible that this unexpectedly large proportion of UC patients with strictures is indicative of long standing aggressive or sub-optimally controlled disease and is concerning. Alternatively, it is also possible that there has been a degree of misclassification of patients with Crohn's disease, suggested by the strictures but also by the high prevalence of fistulas in this 


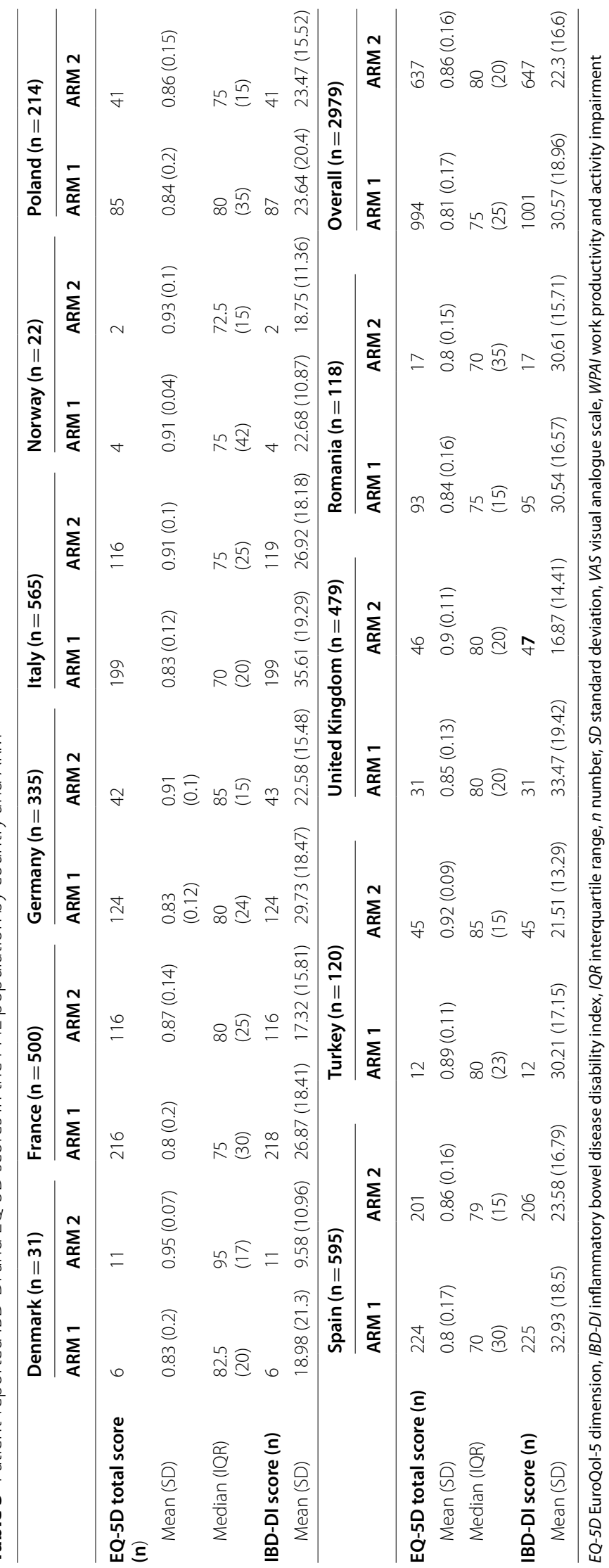




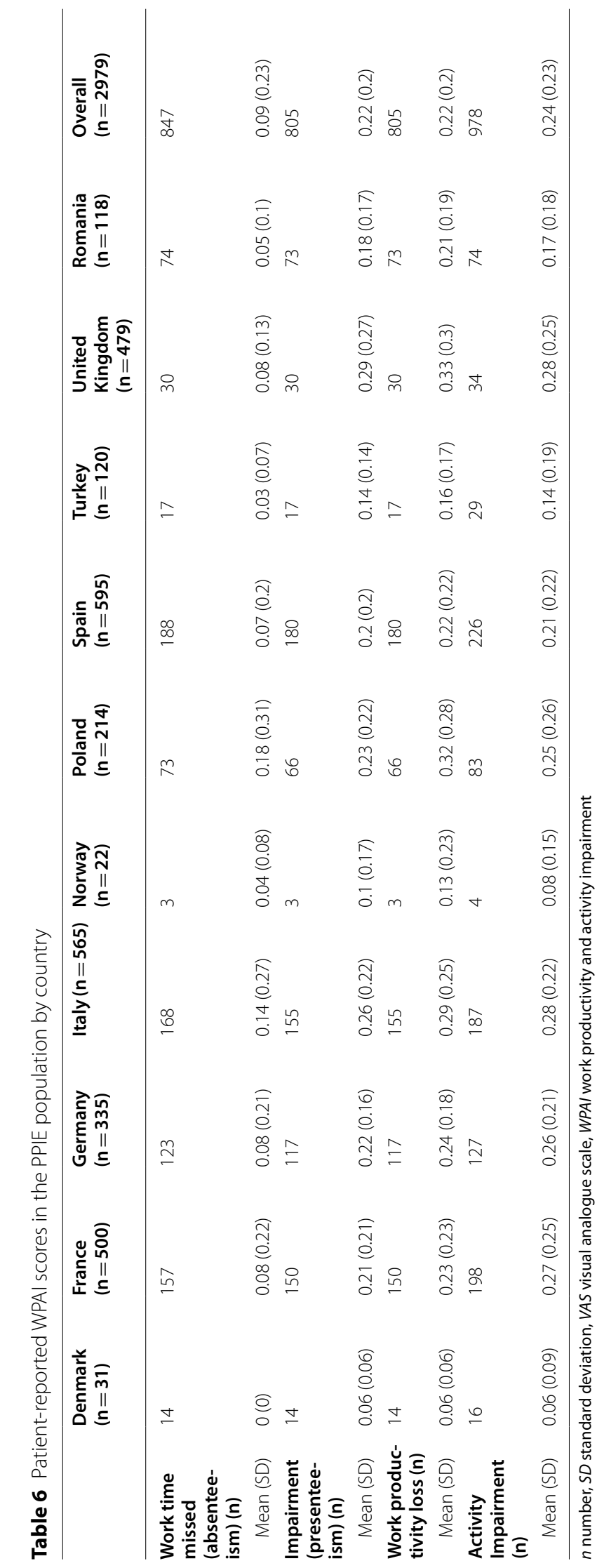


population (10\% and 7\% in arms 1 and 2 respectively). Nevertheless, it is important that the study is reflective of everyday practice, where categorisation of patients may not be straightforward.

Also, the proportion of patients experiencing diarrhoea, rectal bleeding, anaemia, crampy abdominal pain and fatigue in ARM 2 was not far behind that in ARM 1, which could explain to some degree the relatively small differences in costs in the two groups. This raises several questions with respect to quality and perception of disease control. It is possible that sub-optimally controlled disease and the naturally fluctuant disease course therein triggered these symptoms and emphasises the need to treat beyond symptoms aiming for endoscopic remission where possible to mitigate gut injury and active symptoms stemming from sub-optimal disease control [35, 36]. The impact of the wider adoption of a treat to target strategy on optimal disease control and its implications to quality of life represent an area of urgent and unmet research need.

There is increasing awareness that ulcerative colitis is a progressive disease and that long standing disease may lead to complications such as stricturing, dysmotility, anorectal dysfunction and altered colonic permeability which may also be a driver of symptoms such as diarrhoea and incontinence [16, 37, 38].

This study had limitations that must be considered before reaching an overall consensus. Some countries (e.g., Spain) have a much larger population sample than others (e.g., Norway), which could increase the uncertainty of the final costs in the latter. EQ-5D results suggest a low sensitivity to changes in disease severity. Additionally, the short recall period "your health today" of this tool, coupled with the fluctuant nature of UC, challenge the interpretation of these data. Despite physicians having no choice in selection of participants, the next ten patients seen in clinical consultation are selected, selection bias may still be present. Mild patients are more likely to be seen in clinical consultation as the disease is often newly diagnosed. Severe patients are also more likely to be seen in clinical consultation as they need the most attention. This can lead to selection bias against remission and/or moderate patients.

The higher costs in the PPIE population compared with those in the CRF population suggests that the responding patients and the main LUCID population should not be compared directly; this difference would partly explain the EQ5D results being higher than expected and suggesting that there might be a difference (bias) between patients who respond versus those who do not.

\section{Conclusion}

The initial results of this study suggest that there is a significant cost associated with UC management in both arms, with a relatively high cost even for patients that reach remission or mild status. Despite the relatively high EQ-5D scores in the UC population, analysis of IBD-DI, work productivity and indirect costs suggest an unmet need in the UC population, especially in ARM 1 of the study. Furthermore, the high level of symptoms, disease complications, comorbidities and EIMs further reinforce this unmet need. This study provided insight into the per-patient costs within 10 participating European countries with markedly different healthcare provisions and settings, thereby aiding stakeholders with the opportunity to understand the economic landscape of the condition better. The outcomes of the LUCID study will help develop relevant public health actions and policies and help improve UC clinical guidelines.

\section{Abbreviations}

UC: Ulcerative colitis; eCRF: Electronic case report forms; HRQoL: Healthrelated quality of life; PPIE: Public and patient involvement and engagement; IBD: Inflammatory bowel disease; PROMS: Patient reported outcome measures; UoC: University of Chester; GPP: Guidelines for Good Pharmacoepidemiology Practices; ERG: Expert review group; CCUK: Crohns and Colitis UK; WPAI: Work productivity and impairment; EQ-5D: EuroQoL-5D; IBD-DI: Inflammatory bowel disease-disability index; RU: Resource use; SCCAl: Simple clinical colitis activity index; PGA: Physician global assessment; BMI: Body mass index; EIM: Extra Intestinal manifestations.

\section{Supplementary Information}

The online version contains supplementary material available at https://doi. org/10.1186/s12876-021-02028-5.

Additional file 1. Supplementary Table 1. LUCID study cost sources. Supplementary Table 2. Number of physicians and patients returned questionnaires.

\section{Acknowledgements}

Medical writing support was provided by BhamPharma Ltd, UK.

\section{Authors' contributions}

LRC: Conception and design of the study, analysis and interpretation of the data, drafting of draft manuscript and approval of final submitted version. JE: Conception and design of the study, analysis and interpretation of the data, drafting of draft manuscript and approval of final submitted version. AR: Conception and design of the study, revision of draft manuscript and approval of final submitted version. GGP: Conception and design of the study, revision of draft manuscript and approval of final submitted version. AL: Design of the study, revision of draft manuscript and approval of final submitted version. AF: Design of the study, revision of draft manuscript and approval of final submitted version. $\mathrm{BH}$ : Design of the study, revision of draft manuscript and approval of final submitted version. LPB: Design of the study, revision of draft manuscript and approval of final submitted version. AS: Design of the study, revision of draft manuscript and approval of final submitted version. JB: Design of the study, revision of draft manuscript and approval of final submitted version. HT: Design of the study, revision of draft manuscript and approval of final submitted version. LA: Design of the study, revision of draft manuscript and approval of final submitted version. ST: Design of the study, revision of draft manuscript 
and approval of final submitted version. JL: Design of the study, revision of draft manuscript and approval of final submitted version. GF: Design of the study, revision of draft manuscript and approval of final submitted version. All authors have read and approved the manuscript.

\section{Funding}

This work was supported by Eli Lilly and Pfizer internationally, and by Celgene in the UK. No supporters had influence on the design of the study, data collection, analysis and interpretation of the data or writing of the manuscript.

\section{Availability of data and materials}

The data that support the findings of this study are available from HCD ECOnomics but restrictions apply to the availability of these data, which were used under license for the current study, and so are not publicly available. Data are however available from the authors upon reasonable request and with permission of HCD Economics.

\section{Declarations}

\section{Ethics approval and consent to participate}

Ethics approval was provided by the University of Chester research ethics committee. All patients provided consent to participate in the study.

\section{Consent for publication}

Not applicable.

\section{Competing interests}

JB reports personal fees from AbbVie, personal fees from Janssen-Cilag, personal fees from Celgene, personal fees from MSD, personal fees from Pfizer, Grants and personal fees from Takeda, Grants and personal fees from Tillots Pharma, personal fees from Samsung Bioepis, outside the submitted work. JL has received research support from Takeda and consultancy and speaker fees from Abbvie, MSD, Janssen, Pfizer and Takeda. LPB reports personal fees from AbbVie, Janssen, Genentech, Ferring, Tillots, Pharmacosmos, Celltrion, Takeda, Boerhinger Ingelheim, Pfizer, Index Pharmaceuticals, Sandoz, Celgene, Biogen, Samsung Bioepis, Alma, Sterna, Nestle, Enterome, Allergan, MSD, Roche, Arena, Gilead, Hikma, Amgen, BMS, Vifor, Norgine; Mylan, Lilly, Fresenius Kabi, Oppilan Pharma, Sublimity Therapeutics, Applied Molecular Transport, OSE Immunotherapeutics, Enthera, Theravance; Grants from Abbvie, MSD, Takeda; stock options: CTMA. The remaining authors declare no competing interests.

\section{Author details \\ ${ }^{1} \mathrm{HCD}$ Economics, The Innovation Centre, Keckwick Lane, Daresbury, War- rington, England, UK. ${ }^{2}$ Sheffield Teaching Hospitals NHS Foundation Trust, Sheffield, UK. ${ }^{3}$ The University of Sheffield, Sheffield, UK. ${ }^{4}$ University of Chester, Chester, UK. ${ }^{5}$ King's College Hospital NHS Foundation Trust London, London, UK. ${ }^{6}$ University Hospital Centre Nancy, Nancy, France. ${ }^{7}$ DRK Kliniken Berlin, Berlin, Germany. ${ }^{8}$ Hvidovre Hospital, Gastrounit, Hvidovre, Denmark. ${ }^{9}$ Crohn's and Colitis UK, Hatfield, Hertfordshire, UK. ${ }^{10}$ European Federation of Crohn's and Ulcerative Colitis Associations, Brussels, Belgium. ${ }^{11}$ IBDrelief, Brighton, UK. ${ }^{12}$ Istituto Clinico Humanitas, Milan, Italy. ${ }^{13}$ Pennine Acute Hospitals NHS Trust, Manchester, UK.}

Received: 21 August 2020 Accepted: 15 November 2021

Published online: 04 December 2021

\section{References}

1. Tun GS, Harris A, Lobo AJ. Ulcerative colitis: management in adults, children and young people-concise guidance. Clin Med (Lond). 2017;17(5):429-33. https://doi.org/10.7861/clinmedicine.17-5-429.

2. Lamb CA, Kennedy NA, Raine T, Hendy PA, Smith PJ, Limdi JK, et al. British Society of Gastroenterology consensus guidelines on the management of inflammatory bowel disease in adults. Gut. 2019;68(Suppl 3):s1-106. https://doi.org/10.1136/gutjnl-2019-3184843.

3. Magro F, Gionchetti P, Eliakim R, Ardizzone S, Armuzzi A, Barreiro-de Acosta M, Burisch J, Gecse KB, Hart AL, Hindryckx P, Langner C. Third European evidence-based consensus on diagnosis and management of ulcerative colitis. Part 1: definitions, diagnosis, extra-intestinal manifestations, pregnancy, cancer surveillance, surgery, and ileo-anal pouch disorders. J Crohn's Colitis. 2017;11(6):649-70.

4. Ungaro R, Mehandru S, Allen PB, Peyrin-Biroulet L, Colombel J-F. Ulcerative colitis. Lancet. 2017;389(10080):1756-70. https://doi.org/10.1016/ S0140-6736(16)32126-2.

5. Harbord M, Annese V, Vavricka SR, Allez M, Barreiro-de Acosta M, Boberg KM, Burisch J, De Vos M, De Vries AM, Dick AD, Juillerat P. European Crohn's and Colitis Organisation. The first European evidence-based consensus on extra-intestinal manifestations in inflammatory bowel disease. J Crohns Colitis. 2016;10(3):239-54.

6. da Silva BC, Lyra AC, Rocha R, Santana GO. Epidemiology, demographic characteristics and prognostic predictors of ulcerative colitis. World J Gastroenterol. 2014;20(28):9458-67. https://doi.org/10.3748/wjg.v20.i28. 9458.

7. Rubin GP, Hungin AP, Kelly PJ, Ling J. Inflammatory bowel disease: epidemiology and management in an English general practice population. Aliment Pharmacol Ther. 2000;14(12):1553-9. https://doi.org/10.1046/j. 1365-2036.2000.00886.x

8. Russel MG, Dorant E, Volovics A, et al. High incidence of inflammatory bowel disease in The Netherlands: results of a prospective study. The South Limburg IBD Study Group. Dis Colon Rectum. 1998;41 (1):33-40. https://doi.org/10.1007/bf02236893.

9. Shivananda S, Lennard-Jones J, Logan R, et al. Incidence of inflammatory bowel disease across Europe: is there a difference between north and south? Results of the European Collaborative Study on Inflammatory Bowel Disease (EC-IBD). Gut. 1996;39(5):690-7. https://doi.org/10.1136/ gut.39.5.690.

10. Feuerstein JD, Cheifetz AS. Ulcerative colitis: epidemiology, diagnosis, and management. Mayo Clin Proc. 2014;89(11):1553-63. https://doi.org/10. 1016/j.mayocp.2014.07.002.

11. Siegel CA, Whitman CB, Spiegel BM, et al. Development of an index to define overall disease severity in IBD. Gut. 2016. https://doi.org/10.1136/ gutjnl-2016-312648.

12. Knowles SR, Keefer L, Wilding H, Hewitt C, Graff LA, Mikocka-Walus A. Quality of life in inflammatory bowel disease: a systematic review and meta-analyses_part II. Inflamm Bowel Dis. 2018;24(5):966-76.

13. Tribbick D, Salzberg M, Ftanou M, Connell WR, Macrae F, Kamm MA, Bates GW, Cunningham G, Austin DW, Knowles SR. Prevalence of mental health disorders in inflammatory bowel disease: an Australian outpatient cohort. Clin Exp Gastroenterol. 2015;8:197.

14. Bernklev T, Jahnsen J, Henriksen M, Lygren I, Aadland E, Sauar J, Schulz T, Stray N, Vatn M, Moum B. Relationship between sick leave, unemployment, disability, and health-related quality of life in patients with inflammatory bowel disease. Inflamm Bowel Dis. 2006;12(5):402-12.

15. Limsrivilai J, Stidham RW, Govani SM, Waljee AK, Huang W, Higgins PD. Factors that predict high health care utilization and costs for patients with inflammatory bowel diseases. Clin Gastroenterol Hepatol. 2017;15(3):385-92.

16. Nigam GB, Limdi JK, Vasant DH. Current perspectives on the diagnosis and management of functional anorectal disorders in patients with inflammatory bowel disease. Ther Adv Gastroenterol. 2018;11:1756284818816956.

17. Samuel S, Ingle SB, Dhillon S, Yadav S, Harmsen WS, Zinsmeister AR, Tremaine WJ, Sandborn WJ, Loftus EV Jr. Cumulative incidence and risk factors for hospitalization and surgery in a population-based cohort of ulcerative colitis. Inflamm Bowel Dis. 2013;19(9):1858-66.

18. Sulz MC, Siebert U, Arvandi M, Gothe RM, Wurm J, von Känel R, Vavricka SR, Meyenberger C, Sagmeister M, members of the Swiss IBD Cohort Study Group. Predictors for hospitalization and outpatient visits in patients with inflammatory bowel disease: results from the Swiss Inflammatory Bowel Disease Cohort Study. Eur J Gastroenterol Hepatol 2013;25(7):790-7.

19. Odes $\mathrm{S}$, Vardi $\mathrm{H}$, Friger $\mathrm{M}$, et al. Cost analysis and cost determinants in a European inflammatory bowel disease inception cohort with 10 years of follow-up evaluation. Gastroenterology. 2006;131(3):719-28. https://doi. org/10.1053/j.gastro.2006.05.052.

20. Cohen RD, Yu AP, Wu EQ, Xie J, Mulani PM, Chao J. Systematic review: the costs of ulcerative colitis in Western countries. Aliment Pharmacol Ther. 2010;31(7):693-707.

21. van der Valk ME, Mangen MJ, Leenders M, Dijkstra G, van Bodegraven AA, Fidder HH, de Jong DJ, Pierik M, van der Woude CJ, Romberg-Camps 
MJ, Clemens $\mathrm{CH}$. Healthcare costs of inflammatory bowel disease have shifted from hospitalisation and surgery towards anti-TNFa therapy: results from the COIN study. Gut. 2014;63(1):72-9.

22. Prenzler A, Bokemeyer B, von der Schulenburg JM, MittendorfT. Health care costs and their predictors of inflammatory bowel diseases in Germany. Eur J Health Econ. 2011;12(3):273-83.

23. Balestroni G, Bertolotti G. EuroQol-5D (EQ-5D): an instrument for measuring quality of life. Monaldi Arch Chest Dis. 2012;78(3):155-9. https://doi. org/10.4081/monaldi.2012.121.

24. Herdman M, Gudex C, Lloyd A, et al. Development and preliminary testing of the new five-level version of EQ-5D (EQ-5D-5L). Qual Life Res. 2011;20(10):1727-36. https://doi.org/10.1007/s11136-011-9903-X.

25. Gower-Rousseau C, Sarter H, Savoye G, et al. Validation of the inflammatory bowel disease disability index in a population-based cohort. Gut. 2017;66(4):588-96. https://doi.org/10.1136/gutjnl-2015-310151.

26. Bodger K, Ormerod C, Shackcloth D, Harrison M, IBD Control Collaborative. Development and validation of a rapid, generic measure of disease control from the patient's perspective: the IBD-control questionnaire. Gut. 2014;63(7):1092-1102. https://doi.org/10.1136/gutjnl-2013-305600

27. Reilly CM, Bruner DW, Mitchell SA, et al. A literature synthesis of symptom prevalence and severity in persons receiving active cancer treatment. Support Care Cancer. 2013;21(6):1525-50. https://doi.org/10.1007/ s00520-012-1688-0.

28. International Society for Pharmacoepidemiology. Guidelines for Good Pharmacoepidemiology Practices (GPP) — International Society for Pharmacoepidemiology. https://www.pharmacoepi.org/resources/policies/ guidelines-08027/. Accessed 18 Oct 2019.

29. Marri SR, Buchman AL. The education and employment status of patients with inflammatory bowel diseases. Inflamm Bowel Dis. 2005;1 (2):171-7.

30. Kawalec P, Malinowski KP. Indirect health costs in ulcerative colitis and Crohn's disease: a systematic review and meta-analysis. Expert Rev Pharmacoecon Outcomes Res. 2015;15(2):253-66.

31. Longobardi T, Jacobs P, Bernstein CN. Work losses related to inflammatory bowel disease in the United States: results from the National Health Interview Survey. Am J Gastroenterol. 2003;98(5):1064-72.

32. Yamagata M, Mikami T, Tsuruta T, Yokoyama K, Sada M, Kobayashi K, Katsumata T, Koizumi W, Saigenji K, Okayasu I. Submucosal fibrosis and basic-fibroblast growth factor-positive neutrophils correlate with colonic stenosis in cases of ulcerative colitis. Digestion. 2011;84(1):12-21.

33. Gumaste V, Sachar DB, Greenstein AJ. Benign and malignant colorectal strictures in ulcerative colitis. Gut. 1992;33(7):938-41. Ref: Edwards FC, Truelove SC. Course and prognosis of ulcerative colitis. Gut. 1964;5:1-15.

34. Edwards FC, Truelove SC. Course and prognosis of ulcerative colitis. Gut. 1964;5:1-15.

35. Peyrin-Biroulet L, Sandborn W, Sands BE, Reinisch W, Bemelman W, Bryant RV, d'Haens G, Dotan I, Dubinsky M, Feagan B, Fiorino G. Selecting therapeutic targets in inflammatory bowel disease (STRIDE): determining therapeutic goals for treat-to-target. Am J Gastroenterol. 2015;110(9):1324-38.

36. Saxena AP, Limdi JK, Farraye FA. Zeroing in on endoscopic and histologic mucosal healing to reduce the risk of colorectal neoplasia in inflammatory bowel disease. Gastrointest Endosc. 2017;86(6):1012-4.

37. Torres J, Billioud V, Sachar DB, Peyrin-Biroulet L, Colombel JF. Ulcerative colitis as a progressive disease: the forgotten evidence. Inflamm Bowel Dis. 2012;18(7):1356-63.

38. Limdi JK, Vasant DH. Anorectal dysfunction in distal ulcerative colitis: challenges and opportunities for topical therapy. J Crohn's Colitis. 2016;10(4):503.

\section{Publisher's Note}

Springer Nature remains neutral with regard to jurisdictional claims in published maps and institutional affiliations.

Ready to submit your research? Choose BMC and benefit from:

- fast, convenient online submission

- thorough peer review by experienced researchers in your field

- rapid publication on acceptance

- support for research data, including large and complex data types

- gold Open Access which fosters wider collaboration and increased citations

- maximum visibility for your research: over $100 \mathrm{M}$ website views per year

At BMC, research is always in progress.

Learn more biomedcentral.com/submissions 